\title{
Risk of all-cause and CHD mortality in women versus men with type 2 diabetes: a systematic review and meta-analysis
}

Guodong Xu',2,*, Dingyun You ${ }^{3, *}$, Liping Wong ${ }^{4, *}$, Donghui Duan², Fanqian Kong ${ }^{2}$, Xiaohong Zhang², Jinshun Zhao ${ }^{2}$, Wenhua Xing ${ }^{2}$, Liyuan Han² and Li Li ${ }^{1}$

'Department of Endocrinology and Metabolism, Ningbo First Hospital, Ningbo, ${ }^{2}$ Department of Epidemiology, Zhejiang Provincial Key Laboratory of Pathophysiology, School of Medicine, Ningbo University, Ningbo, ${ }^{3}$ Department of Science and Technology, Kunming Medical University, Kunming, China, and ${ }^{4}$ Department of Social and Preventive Medicine, Faculty of Medicine, University of Malaya, Kuala Lumpur, Malaysia

Correspondence should be addressed to L Li or L Han or W Xing Email

lilyningbo@163.com or hanliyuan@nbu.edu.cn or xingwenhua@nbu.edu.cn

\section{Abstract}

Objective: Previous studies have shown sex-specific differences in all-cause and CHD mortality in type 2 diabetes. We performed a systematic review and meta-analysis to provide a global picture of the estimated influence of type 2 diabetes on the risk of all-cause and CHD mortality in women vs men.

Methods: We systematically searched PubMed, EMBASE and Web of Science for studies published from their starting dates to Aug 7, 2018. The sex-specific hazard ratios (HRs) and their pooled ratio (women vs men) of all-cause and CHD mortality associated with type 2 diabetes were obtained through an inverse variance-weighted random-effects metaanalysis. Subgroup analyses were used to explore the potential sources of heterogeneity.

Results: The 35 analyzed prospective cohort studies included 2314292 individuals, among whom 254038 all-cause deaths occurred. The pooled women vs men ratio of the HRs for all-cause and CHD mortality were $1.17(95 \% \mathrm{Cl}$ : $\left.1.12-1.23, I^{2}=81.6 \%\right)$ and $1.97\left(95 \% \mathrm{Cl}: 1.49-2.61, I^{2}=86.4 \%\right)$, respectively. The pooled estimate of the HR for all-cause mortality was approximately 1.30 in articles in which the duration of follow-up was longer than 10 years and 1.10 in articles in which the duration of follow-up was less than 10 years. The pooled HRs for all-cause mortality in patients with type 2 diabetes was 2.33 (95\% Cl: 2.02-2.69) in women and 1.91 (95\% Cl: 1.72-2.12) in men, compared with their healthy counterparts.

Conclusions: The effect of diabetes on all-cause and CHD mortality is approximately 17 and $97 \%$ greater, respectively, for women than for men.

\section{Introduction}

Diabetes is recognized as the world's fastest growing chronic condition. Due to rapid increases in the prevalence of physical inactivity, overweight and obesity, the number of people with diabetes is projected to rise to 592 million by 2035 (1). In particular, type 2 diabetes (T2D) has attained the status of a global pandemic, with the total number of patients with T2D estimated at 425 million in 2015 (2).

Accumulating evidence documents $\mathrm{T} 2 \mathrm{D}$ as an independent risk factor for all-cause mortality $(3,4,5,6)$. The risk of all-cause mortality in persons with T2D is approximately doubled (7). However, these conclusions https://eje.bioscientifica.com https://doi.org/10.1530/EJE-18-0792 (c) 2019 The authors Published by Bioscientifica Ltd. Printed in Great Britain

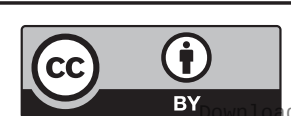

This work is licensed under a Creative Commons Attribution 4.0 International License. 
are mainly based on the assumption that the risk of diabetes in women is the same as in men (8). However, evidence is accruing that the detrimental effects of diabetes are higher among women than among men (9). The sex-based difference in the risk of diabetes would not only result from patient management and treatment (10) but also from the diversity of biological factors (11). Epidemiological studies reported that women with T2D had a higher risk of mortality from cardiovascular diseases $(10,12)$ and cancer (13) than men.

However, the differences between men and women in the risk of all-cause and CHD mortality is still unclear. Moreover, none of the relevant meta-analyses summarized the differences in risk of all-cause and CHD mortality between men and women. Therefore, we performed a comprehensive meta-analysis to estimate reliably the effect of T2D on all-cause and CHD risk among women in comparison with men.

\section{Methods}

\section{Search strategy}

We systematically searched the PubMed (www.ncbi.nlm. nih.gov), EMBASE and Web of Science databases (from their starting dates to Aug 7, 2018) with the limitations object human and language English. A combined text word and medical subject heading (MeSH) search strategy was applied with the terms 'mortality', 'death', 'Diabetes Mellitus, Type 2', 'Adult-Onset Diabetes', 'NonInsulin-Dependent Diabetes', 'Gender', 'Sex', 'Cohort', 'Prospective' and 'Longitudinal'. We also scanned the reference lists of relevant reviews and meta-analyses to discern additional potentially relevant literature.

\section{Inclusion and exclusion criteria}

We included articles only when they had clearly reported hazard ratios (HRs) or equivalents for all-cause or CHD mortality in both genders (T2D patients vs healthy counterparts). We also included articles that did not report HRs for each gender directly, but from which we could calculate it. Studies in which the enrolled participants had stroke, coronary heart disease or other cardiovascular diseases (myocardial infarction, atherosclerosis etc.) were excluded. If more than two articles had been published about the same cohort, we enrolled the one with the longer follow-up period or a larger sample size. The search strategy and inclusion criteria were defined and agreed upon by all the authors. The quality of the included studies was evaluated by the NOS (Newcastle-Ottawa Scale) (14) (Supplementary data, see section on supplementary data given at the end of this article). Our meta-analysis was performed in accordance with the PRISMA statement (15) and registered at the International Prospective Register of Systematic Reviews (Prospero) (http://www.crd.york.ac.uk /PROSPERO, registration number: CRD42017074187).

\section{Data extraction}

For each study, we extracted the following variables: name of first author and study, baseline years of study, country of study, duration of follow-up, mean ages of participants, sample size, death count, adjusted variables, HRs and their 95\% CIs in men and women and NOS score. Two authors (Guodong Xu and Dingyun You) independently extracted the data. If there was controversy, the discrepancy was resolved by an arbitrator (Liyuan Han).

\section{Statistical analysis}

We extracted gender-specific HRs and 95\% CIs from each study (T2D patients vs healthy counterparts). Subsequently, gender-specific HRs and 95\% CIs were used to estimate the pooled ratio of HR and the corresponding 95\% CIs. Subgroup analyses were performed by year of study baseline (before 1980, 1980 to 1990 and after 1990); region (America, Europe, Asia, and Australia, Canada, New Zealand or Pacific); duration of study $(<10,10-14$, $>14$ years); study quality (NOS score) ( $\geq 6$ vs $<6$ ) (14) and adjusted status (unadjusted vs adjusted). Sensitivity analysis was conducted to ascertain the stability of the pooled results after removing one study at a time. The $I^{2}$ value was used to estimate heterogeneity. An $I^{2}$ value of 25, 50 and 75\% represented a low, middle and high degree of heterogeneity, respectively (16). Metaregression analyses were also performed to estimate the source of heterogeneity. We used funnel plots to estimate publication bias. Egger's and Begg's test were also applied to quantitatively estimate publication bias. Additionally, to explore the possible effect of publication bias, we employed trim-and-fill method (17) in our meta-analyses for more reliable estimates. All $P$ values were two sided and $P$ values less than 0.05 were considered as statistically significant. Software Stata 12.0 (StataCorp) was used to perform statistical analyses. 


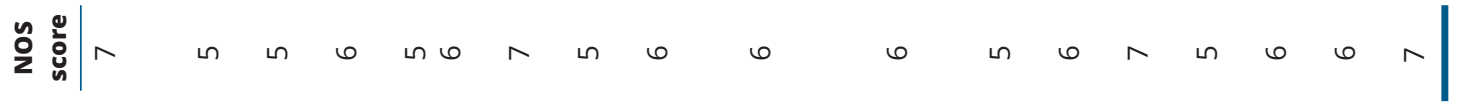

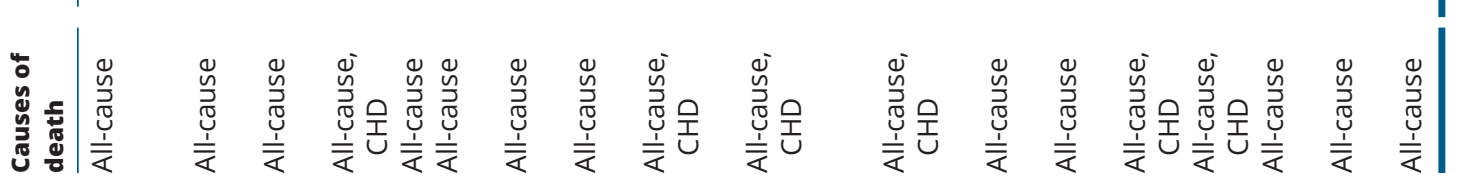

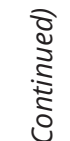
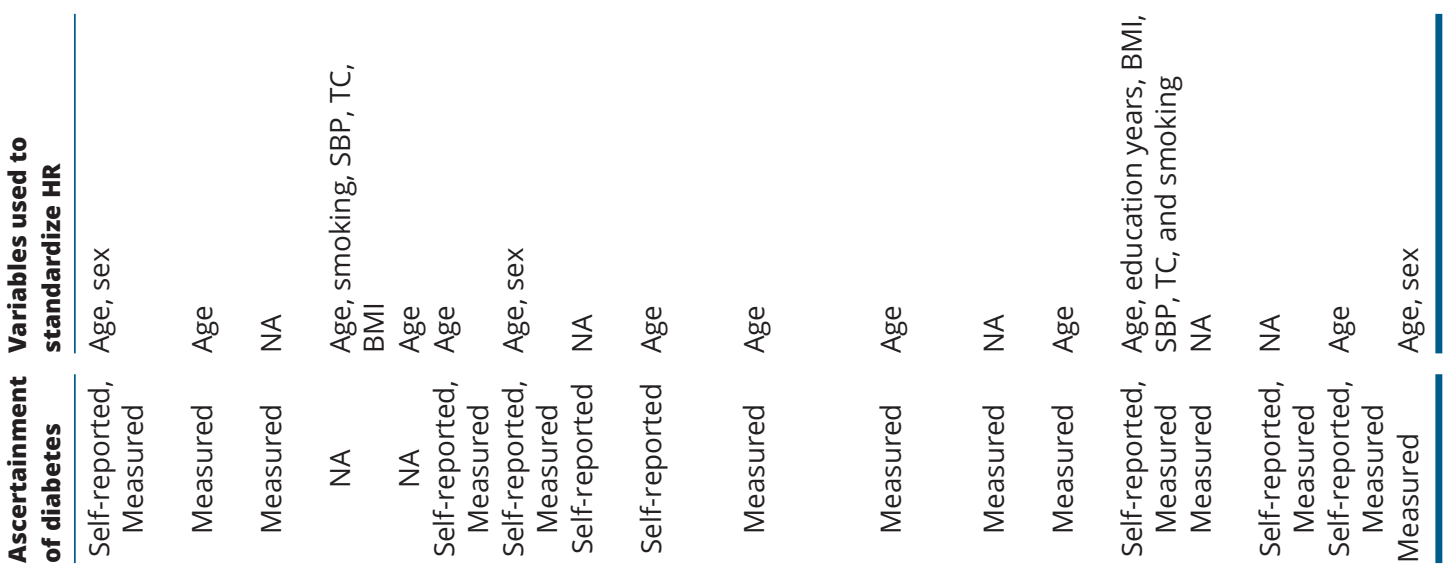

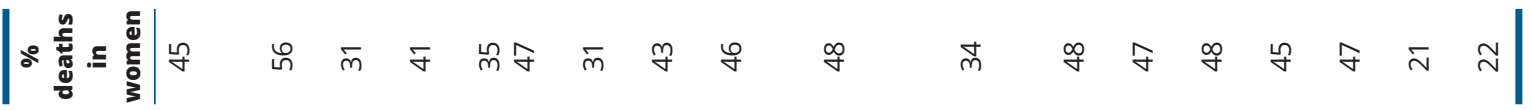

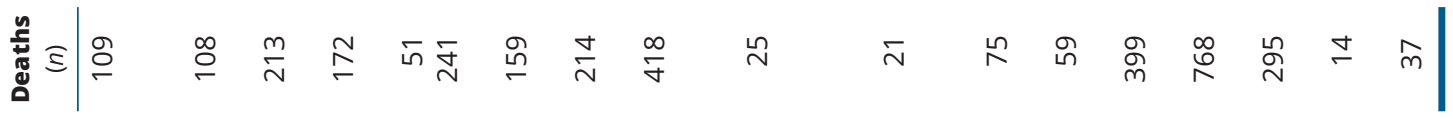

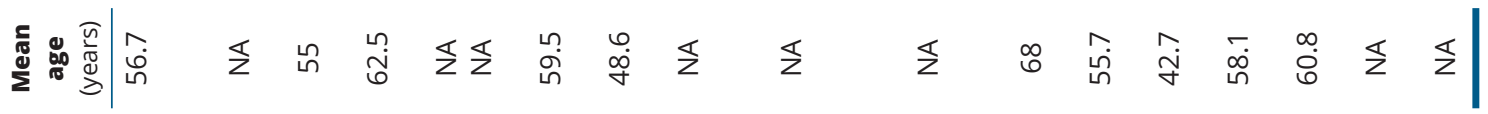

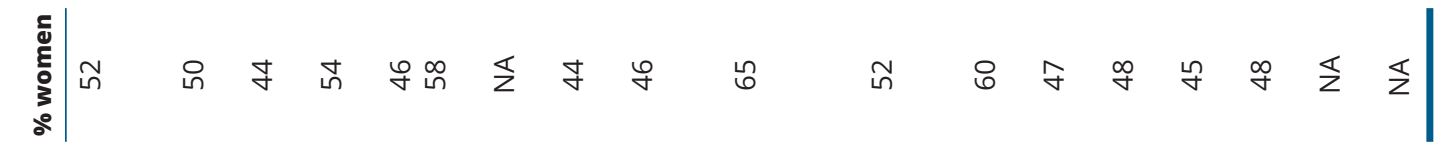
荧

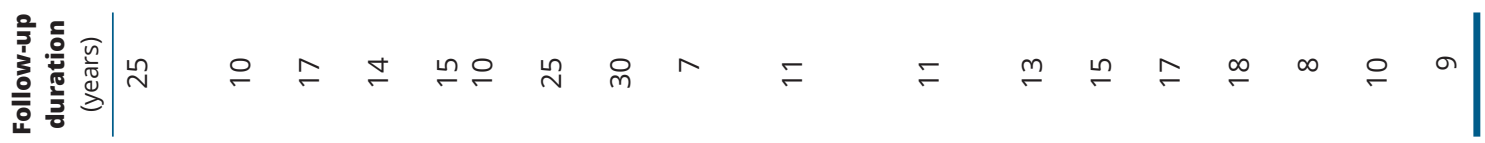

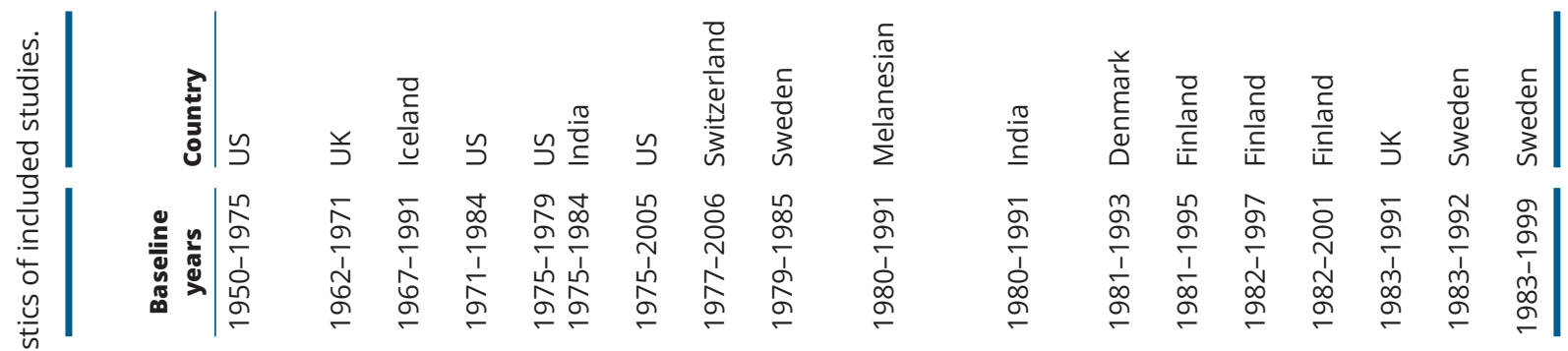

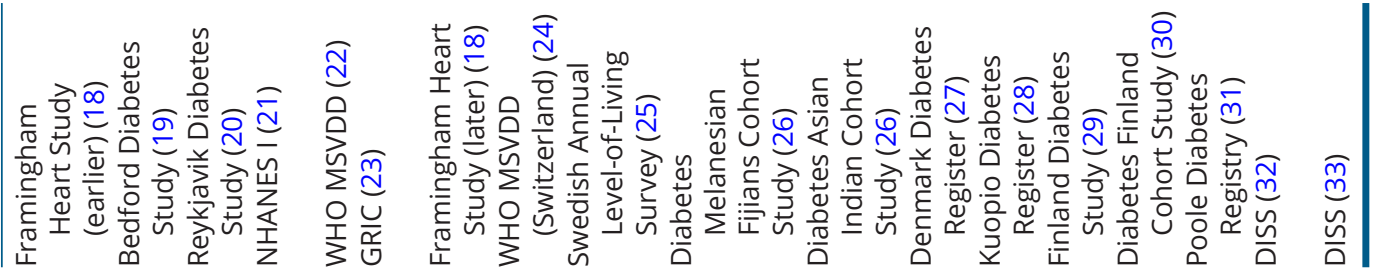




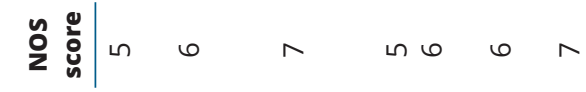

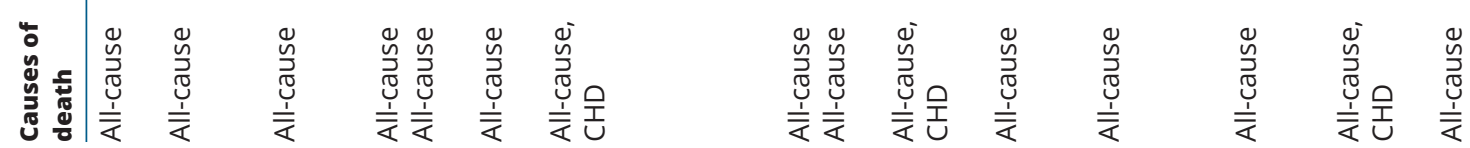
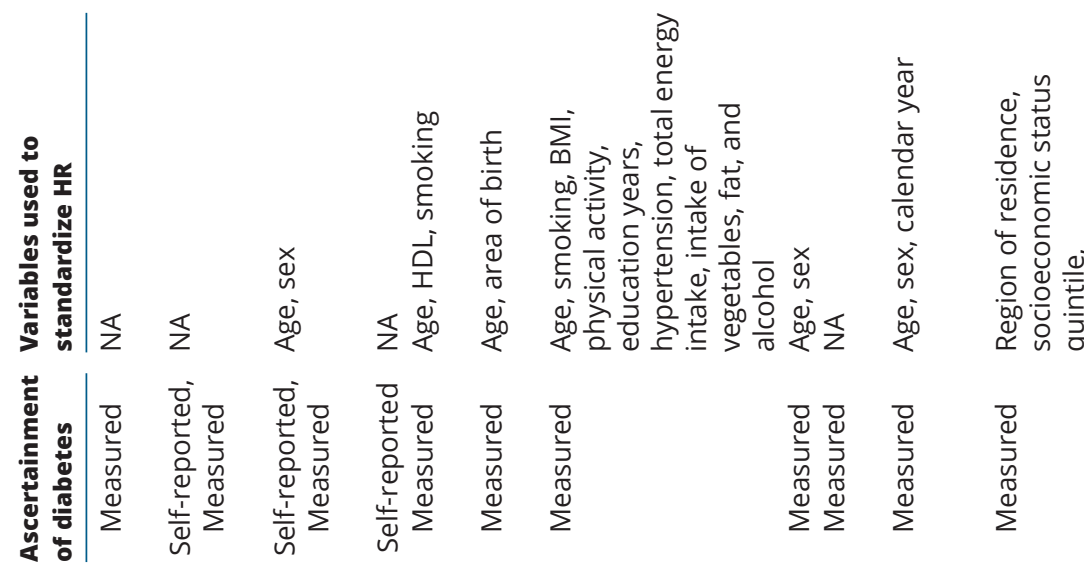

>

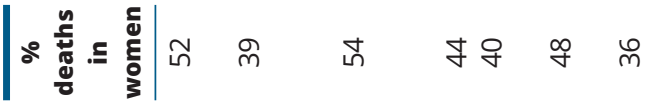

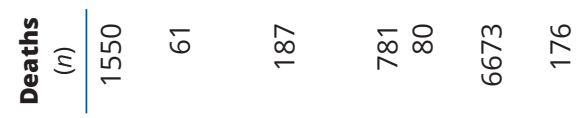

乏

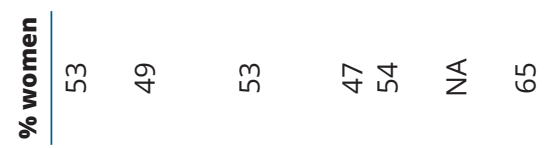

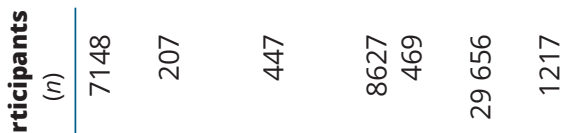

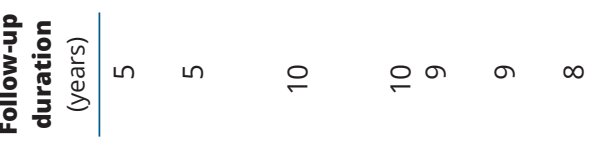

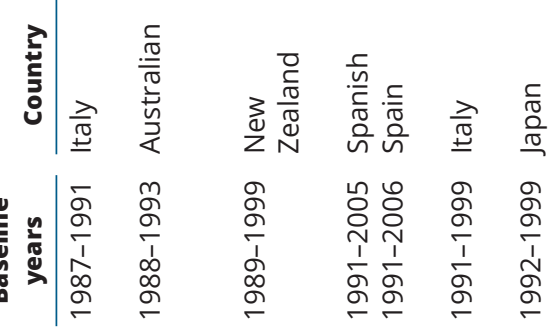

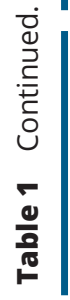

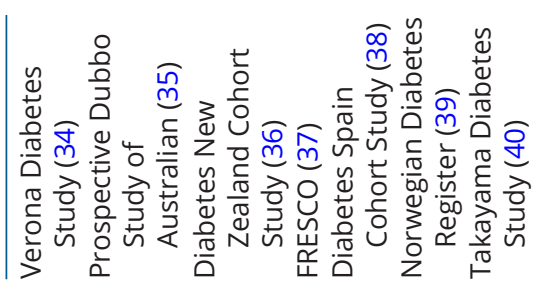

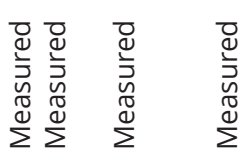

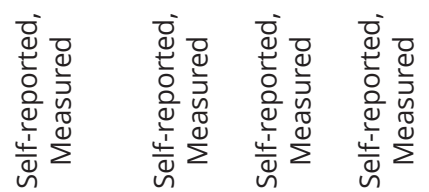

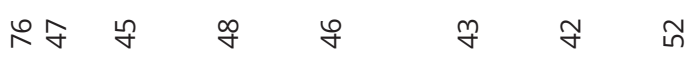

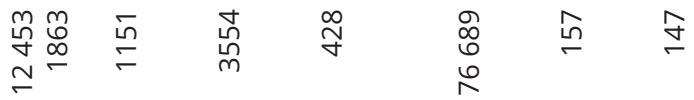

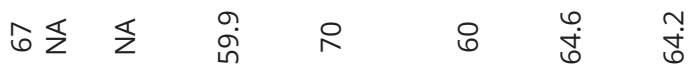

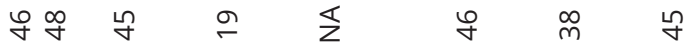

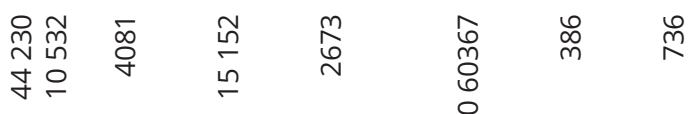

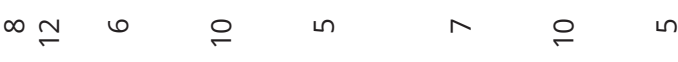

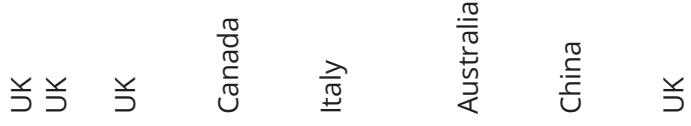

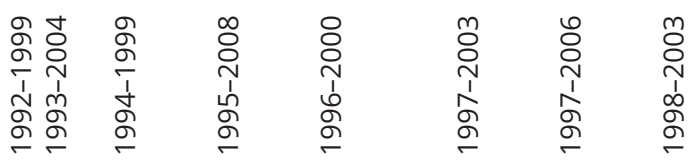

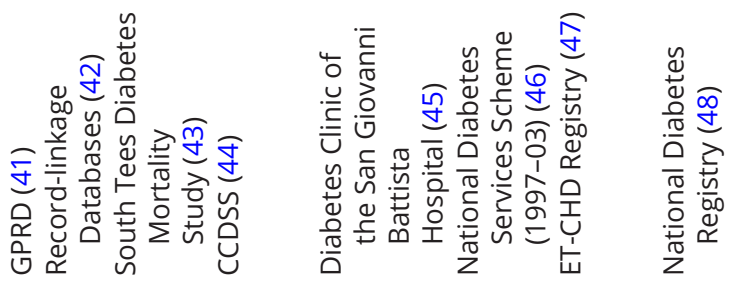


$\begin{array}{lll}n & \wedge \\ \text { 온 운 운 }\end{array}$

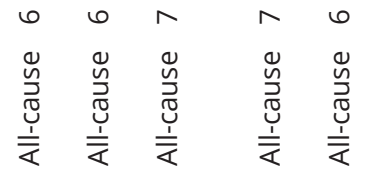
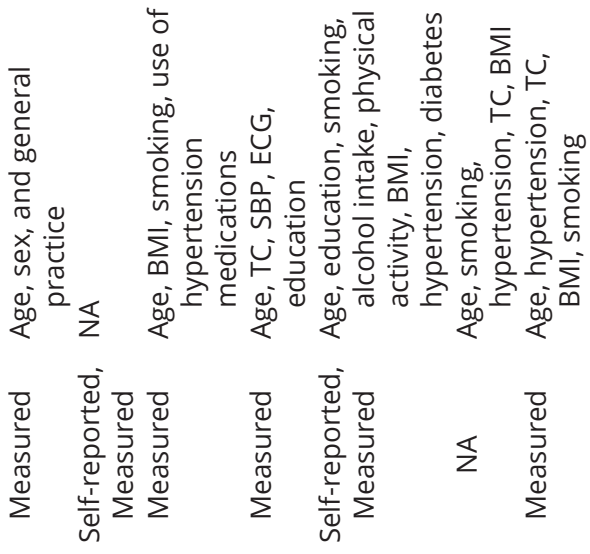

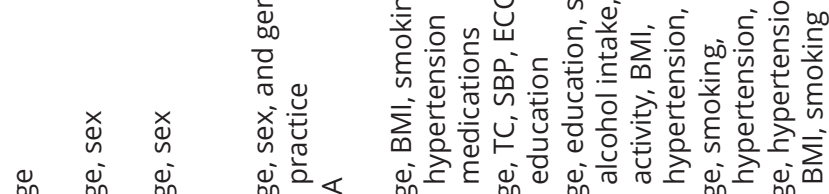
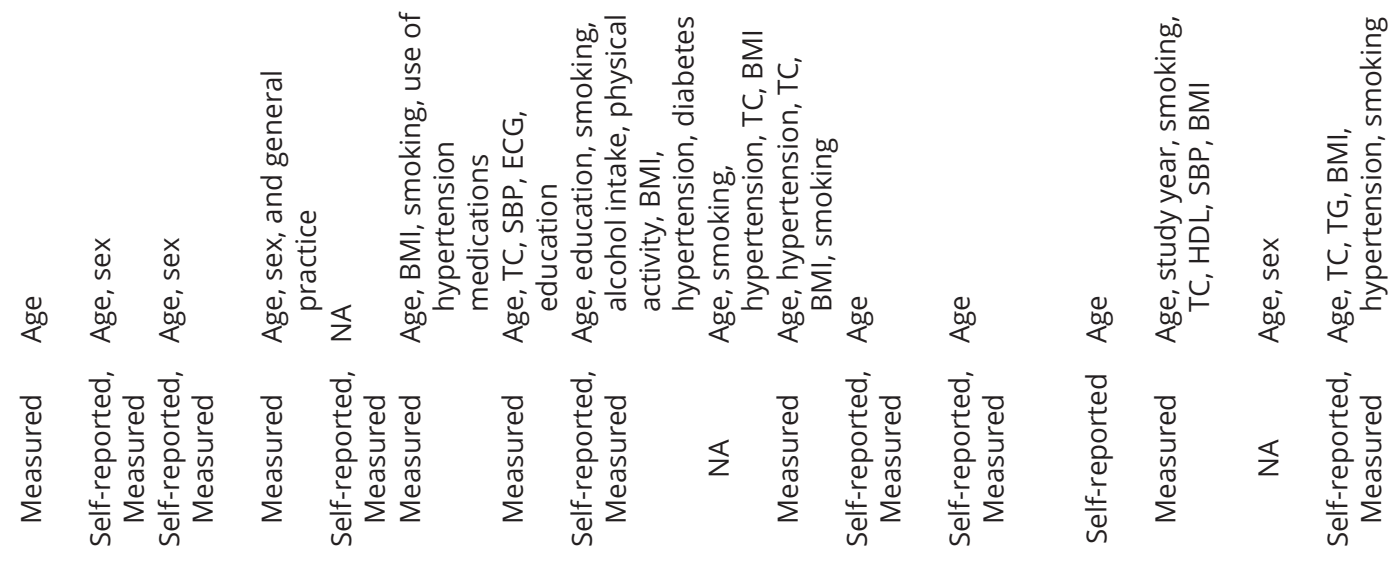

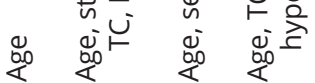

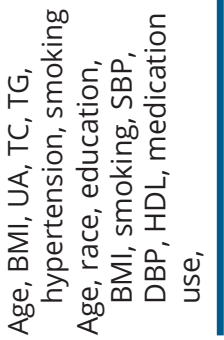

$$
\text { ษ } タ
$$

$\therefore \stackrel{m}{\stackrel{m}{m}} \underset{m}{\stackrel{m}{m}}$

ก กิ ถึก

$\stackrel{乛}{\ulcorner}$

เท

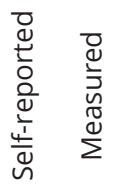

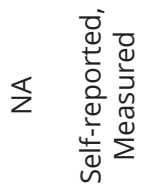

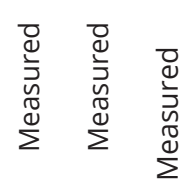

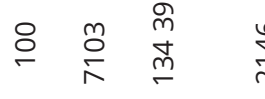

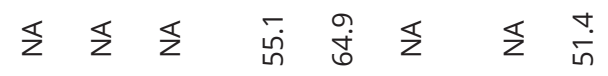

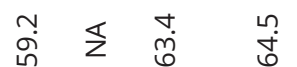

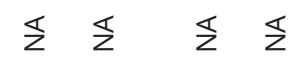

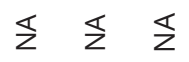

$\stackrel{\infty}{m} \stackrel{\infty}{+}$

ㅇ

每 8

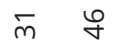

ชิ $\stackrel{\infty}{m}$ ๆ

$\infty$

กิ กี

$\stackrel{\infty}{m}$ i̊ $\stackrel{\text { in }}{m}$

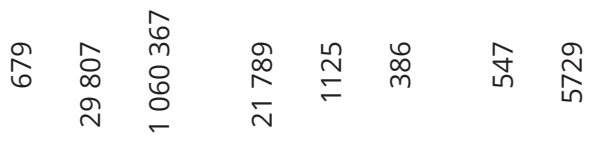

\& $\stackrel{\infty}{\lessgtr}$

$\stackrel{0}{\aleph}$

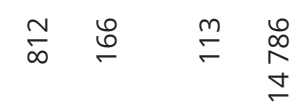

$\stackrel{\infty}{m} \stackrel{m}{\stackrel{N}{N}}$

$\wedge m \wedge$

유

$0 \mp$ ก $\simeq$

$\div \simeq \infty$

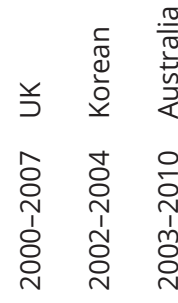

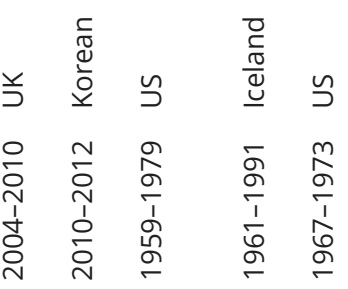

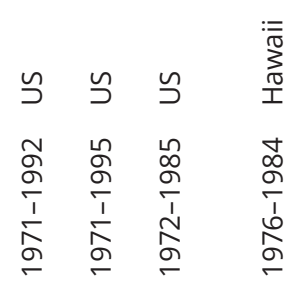

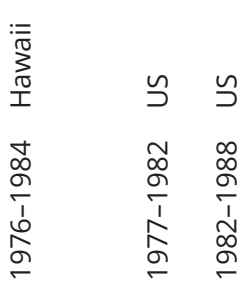

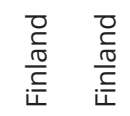

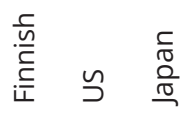

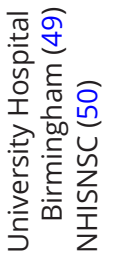

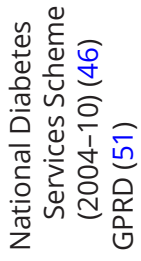

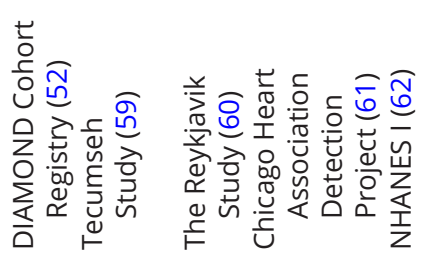

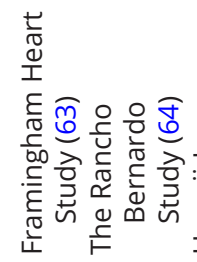

ชิ

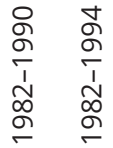

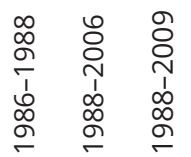




\section{Results}

\section{Study characteristics}

We systematically searched PubMed, EMBASE and Web of Science (from their starting dates to Aug 7, 2018). A total of 3907 articles were identified by assessment of titles and abstracts, and eight additional records were identified from the reference lists (Supplementary Fig. 1). After fulltext assessment, 35 articles were finally included in our meta-analysis $(18,19,20,21,22,23,24,25,26,27,28,29$, $30,31,32,33,34,35,36,37,38,39,40,41,42,43,44,45$, $46,47,48,49,50,51,52)$ for all-cause mortality, and 24 articles for CHD mortality $(21,25,26,29,30,40,43,47$, $53,54,55,56,57,58,59,60,61,62,63,64,65,66)$. Table 1 shows the baseline characteristics of all 52 cohorts. A total of 2314292 T2D cases (46\% women) were included, and 254038 all-cause deaths (45\% women) occurred. Among the 35 datasets included, 23 cohort studies were performed in Europe $(19,20,24,25,27,28,29,30,31$, $32,33,34,36,37,38,39,41,42,43,45,48,49,51), 5$ in Australia, Canada, New Zealand or Pacific (22, 26, 35, 44, 46), 3 in America $(18,21,22)$ and 6 in Asia $(23,26,40,47$, $50,52)$. All the included articles had NOS scores higher than four points, and 26 of them scored at least six points $(18,21,23,25,26,28,29,31,32,33,35,36,38,39,40$, $41,43,44,46,47,48,49,50,51,52)$.

\section{HRs for all-cause and CHD mortality between men and women}

The effect of diabetes on all-cause mortality is $17 \%$ higher in women than men (HR 1.17. (95\% CI: 1.12-1.23)) (Fig. 1). The pooled women vs men HR for CHD mortality was 1.97 (95\% CI: 1.49-2.61) (Fig. 2). However, the $I^{2}$ value of 81.6 and $86.4 \%$, respectively, implying the possibility of significant heterogeneity between studies. The pooled HR for all-cause mortality in patients with T2D was 2.33 (95\% CI: 2.20-2.69) in women (Supplementary Fig. 3) and 1.91 (95\% CI: 1.72-2.12) in men (Supplementary Fig. 4), when compared with their healthy counterparts. The pooled HR for CHD mortality in patients with T2D was 3.79 (95\% CI: 3.01-4.78) in women (Supplementary Fig. 5) and 2.13 (95\% CI: 1.86-2.44) in men (Supplementary Fig. 6), when compared with their healthy counterparts.

\section{Subgroup analysis}

We used subgroup analysis to explore the sources of heterogeneity. The year in which the study began did not 


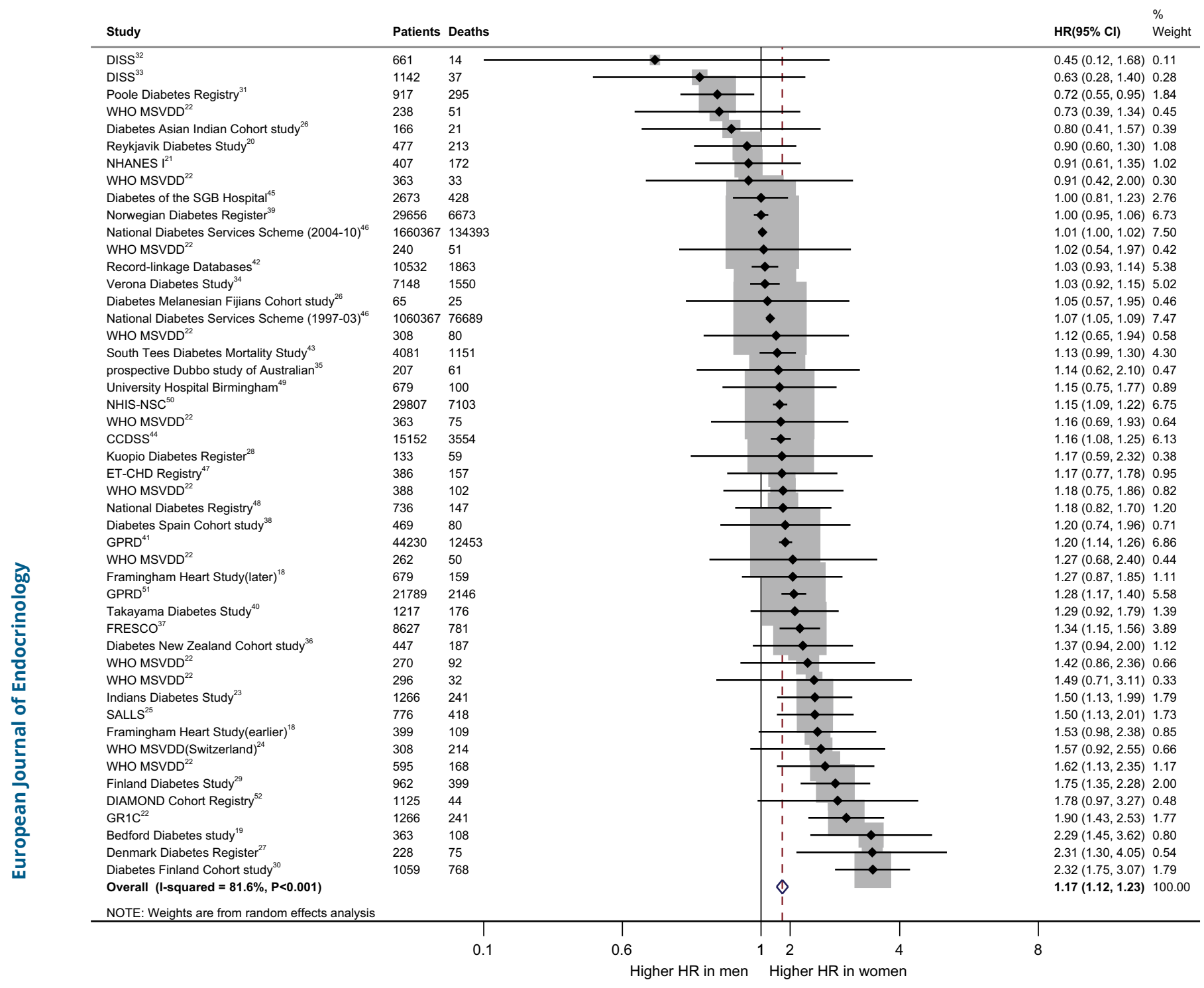

Figure 1

Pooled women-to-men ratios of HRs for all-cause mortality, comparing people with type 2 diabetes vs those without the disorder. CCDSS, Canadian Chronic Diseases: Surveillance System; DISS, Diabetes Incidence Study in Sweden; ET-CHD, Eastern Taiwan integrated health care delivery system of Coronary Heart Disease; FRESCO, Función de Riesgo ESpañola de acontecimientos Coronarios y Otros; GPRD, General Practice Research Database; GR1C, Gila River Indian Community; HR, hazard ratio; MSVDD, Multinational Study of Vascular Disease in Disease in Diabetes; NHANES, the National Health and Nutrition Examination Survey; NHISNSC, National Health Insurance Service-National Sample Cohort.

explain the possible heterogeneity in our study $(P=0.072)$ (Fig. 3). Different quality scores between articles also did not account for the heterogeneity $(P=0.388)$. The presence or absence of adjustment for confounding factors in the articles also not the cause of heterogeneity $(P=0.729)$. The different regions and follow-up duration explained some of the heterogeneities ( $P=0.035$ and $P=0.014$, respectively).
However, the result of meta-regression indicated that the different regions had no effect on the pooled estimate of the HR (All $P>0.05)$, and study duration less than 10 years may be a source of heterogeneity $(P=0.035)$. The pooled estimate of the HR was 1.30 (95\% CI: 1.12-1.52) in the articles with a follow-up duration longer than 15 years, compared with 1.33 (95\% CI: 1.15-1.53) and 1.10 


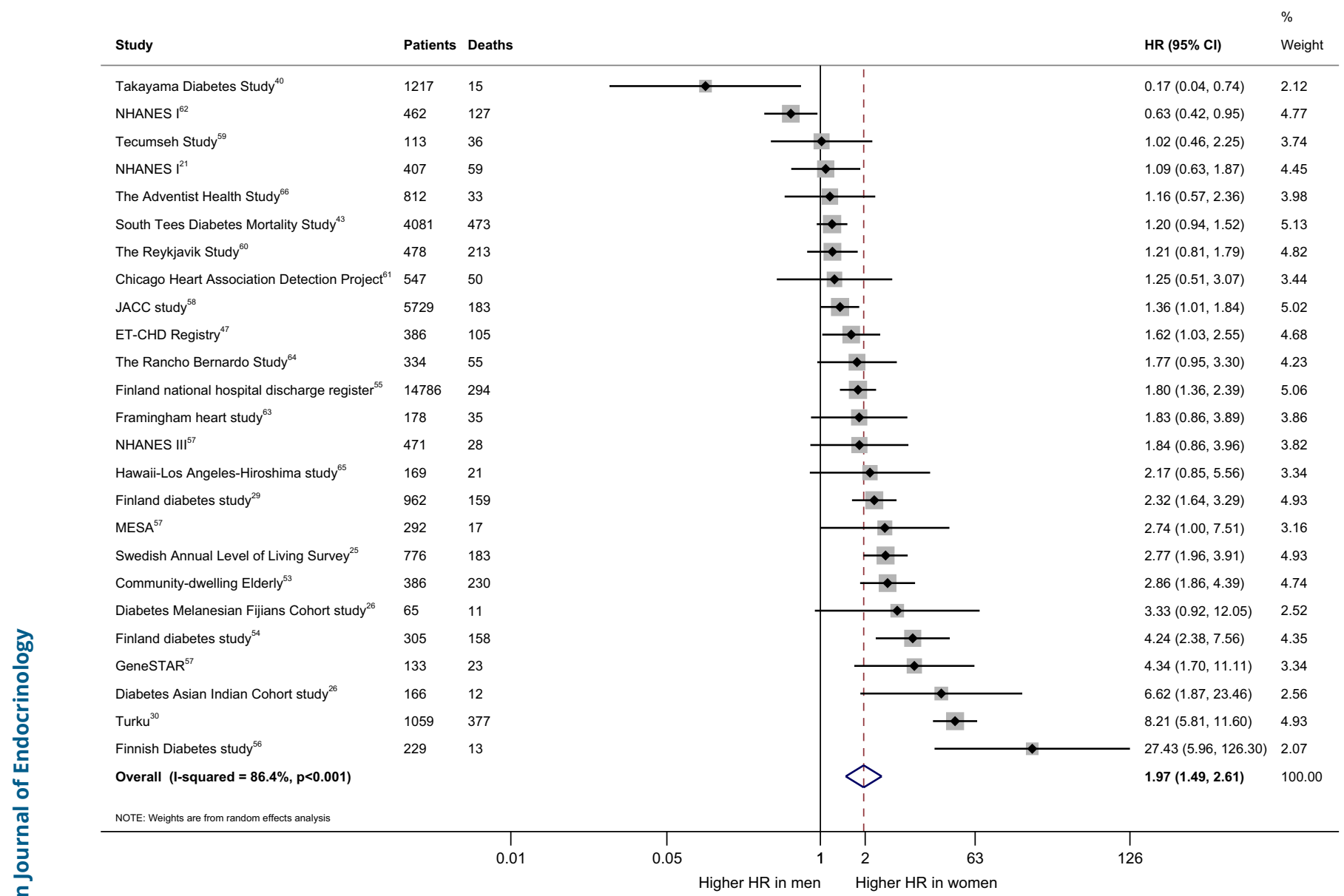

\section{Figure 2}

Pooled women-to-men ratios of HRs for CHD mortality, comparing people with type 2 diabetes vs those without the disorder. ET-CHD, Eastern Taiwan integrated health care delivery system of Coronary Heart Disease; HR, hazard ratio; JACC, The Japan Collaborative Cohort Study; MESA, Multi-Ethnic Study of Atherosclerosis; NHANES, the National Health and Nutrition Examination Survey.

(95\% CI: 1.05-1.15) in those with a follow-up duration between 10 and 15 years and less than 10 years, respectively.

\section{Sensitivity analysis and publication bias}

Sensitivity analysis did not change the results of this metaanalysis. The Begg's funnel plot was used to estimate the potential for publication bias (Supplementary Fig. 2). The result of Begg's test $(P=0.001)$ indicated the possibility of publication bias in all-cause mortality. The trim-andfill method was applied to test and adjust for publication bias, which conservatively hypothesized publication bias is the reason for funnel plot asymmetry. Some negative unpublished studies were used to produce a symmetrical funnel plot (Supplementary Fig. 2), which continued to reveal a statistically significant sex-specific association between T2D and all-cause mortality (HR: 1.08. (95\% CI: 1.03-1.13)).

\section{Discussion}

In this meta-analysis of 35 prospective cohort studies, which included data for more than 2314292 individuals and 254038 all-cause mortality events, T2D was demonstrated as one of the risk factor for allcause and CHD mortality in both women and men. Diabetes-related mortality was higher in women than men, and the effect of diabetes on all-cause and CHD mortality was 17 and 97\% higher in women than men, respectively. 


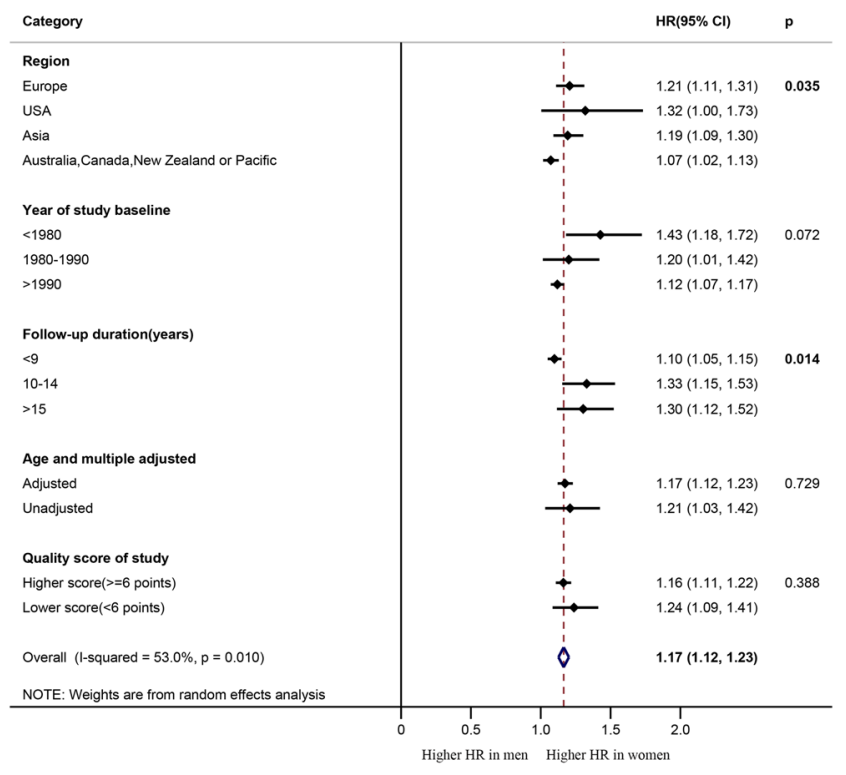

\section{Figure 3}

Forest plot of the subgroup analyses with pooled women-tomen ratios of HRs for all-cause mortality. HR, hazard ratio.

Similarly, the effect of type 1 diabetes on mortality was $37 \%$ higher in women than men (67). In a recent collaborative meta-analysis, diabetes was associated with all-cause mortality, and the relative risks were 1.59 in men and 2.00 in women, respectively (68). It is not clear why the rate of diabetes-related death was higher in women than in men, but several mechanisms could help to explain. One hypothesis is that the excess risk of mortality in women is due to the combined effect of greater deterioration and more prolonged exposure to cardiovascular risk profile during their prediabetic period $(12,67,69)$. Due to their poorer glycemic control, women with diabetes had an overall greater cumulative lifetime exposure to hyperglycemia (12). Several studies have suggested that women with diabetes had higher BMI (70, 71,72 ) and were more insulin resistant (72) than their men counterparts. And they also had significantly higher blood pressure and lipid levels than in men (12).

Research indicates that men with diabetes were diagnosed earlier than women (73), as the early symptoms of diabetes in man may be more likely to be recognized by physicians (74). Men with diabetes may receive better therapeutic interventions and more comprehensive care $(75,76,77)$. Alternatively, sex differences in the management and treatment of diabetes may play a crucial role in the disparity in mortality rates between men and women (74). In addition, men with diabetes are more likely to use aspirin (78), which was proven to decrease the risk of stroke and myocardial infarction $(79,80)$. Furthermore, it has been reported that more diabetic men than women received recommended care processes (62 vs $58 \%$ ) (77). Notably, even under the same treatment regimen, women were less likely than men to achieve treatment targets for controlling mortality risk factors (81, 82). Moreover, it has been reported that women were less likely to achieve glycemic targets with insulin glargine and exhibited significantly less reductions in fasting blood glucose levels (83). Previous research also observed that women were more likely to experience hypoglycemia during insulin treatment $(84,85)$. Therefore, differences in treatment and management may explain a large component of the excess risk associated with diabetes in women. In addition, women have less stroke risk factors compared with men (86), so the effect of adding one risk factor (such as diabetes) on women may be more serious.

The other potential mechanisms for sex-specific differences in mortality may result from the differences in biological factors. A recent study (87) suggested that diabetic women had higher levels of endogenous testosterone, which could predict incident $\mathrm{CHD}$ risk $(88,89)$. Women with diabetes also had a greater change in insulin resistance than men (90). Mansfield and colleagues also found sex-based differences in the level of coagulation and fibrinolysis in individuals with diabetes $(91,92)$ and reported that factor VII and plasminogen activator inhibitor 1 activity levels were significantly higher in women than in men, contributing to the increased cardiovascular risk. Furthermore, higher levels of adiponectin were associated with all-cause mortality in people with T2D $(92,93)$, and diabetic women were found to have higher levels of adiponectin (92).

The large sample size is one of the strengths of this meta-analysis. We are also the first study to estimate reliably the effect of T2D on CHD mortality risk among women in comparison with men. Additionally, the included studies were limited to prospective cohort studies, which eliminated the possible recall and selection bias. The subgroup and sensitivity analysis was used to explore the possible heterogeneity and ensure the reliability of the results. The trim-and-fill method was applied to adjust the potential publication bias. For the quality control of this meta-analysis, we also registered it at Prospero and performed the study in accordance with the PRISMA statement.

However, there were several limitations in our metaanalysis. Firstly, the standard definition of diabetes and 
confounding variables adjusted varied across studies, which may have resulted in inconsistent estimation of mortality risks. Secondly, the follow-up duration of T2D was not directly reported in some studies. Moreover, in most studies, diabetic status was mainly based on selfreport or past medical history; therefore, there was a higher probability of underestimation of the number of patients with T2D. Although we performed a range of sensitivity analyses, we were also unable to explain most of the heterogeneity among the studies for the outcome of all-cause mortality. In addition, some articles lacked specific data on patient's age; therefore, we could not perform age-specific subgroup analysis.

Taken together, we found that the relative effect of diabetes on all-cause and CHD mortality was significantly greater in women than in their men counterparts. For future, we should avoid sexual prejudice in diabetes, take all necessary steps to diagnose early and control risk factors comprehensively to guarantee the most suitable treatments in women patients. Besides, it is necessary to perform further studies to determine the actual mechanisms that account for sex-based difference in diabetes-related mortality risk.

\section{Supplementary data}

This is linked to the online version of the paper at https://doi.org/10.1530/ EJE-18-0792.

\section{Declaration of interest}

The authors declare that there is no conflict of interest that could be perceived as prejudicing the impartiality of this study.

\section{Funding}

The study is supported by Natural Science Foundation of Zhejiang Province (LY17H260002), K C Wong Magna Fund in Ningbo University, China Postdoctoral Science Foundation funded project (156458), Jiangsu Postdoctoral Science Foundation funded project (1601121B), Natural Science Foundation of Ningbo (2016A610169), Public welfare technology and policy science (soft science) application research of Zhejiang Province (2017C35006), Ningbo Scientific Innovation Team for Environmental Hazardous Factor Control and Prevention (2016C51001), Project of Science and Technology Innovation for College Students in Zhejiang Province (2018R405092), Sanming Project of Medicine in Shenzhen (SZSM201803080).

\section{Author contribution statement}

$L H, L L$ and $D Y$ conceived the study, interpreted the data and drafted and critically revised the report. $G X, J Y X$ and $L W$ did the search, analyzed and interpreted the data and critically revised the report. J Z, X Z and L N $\mathrm{Z}$ critically revised the report. D D and F K participated in data collection, oversaw the data analysis and interpreted the data.

\section{References}

1 Guariguata L, Whiting DR, Hambleton I, Beagley J, Linnenkamp U \& Shaw JE. Global estimates of diabetes prevalence for 2013 and projections for 2035. Diabetes Research and Clinical Practice 2014103 137-149. (https://doi.org/10.1016/j.diabres.2013.11.002)

2 GBD 2015 Disease and Injury Incidence and Prevalence Collaborators. Global, regional, and national incidence, prevalence, and years lived with disability for 310 diseases and injuries, 1990-2015: a systematic analysis for the Global Burden of Disease Study 2015. Lancet 2016388 1545-1602. (https://doi.org/10.1016/ S0140-6736(16)31678-6)

3 Almdal T, Scharling H, Jensen JS \& Vestergaard H. The independent effect of type 2 diabetes mellitus on ischemic heart disease, stroke, and death: a population-based study of 13,000 men and women with 20 years of follow-up. Archives of Internal Medicine 2004164 1422-1426. (https://doi.org/10.1001/archinte.164.13.1422)

4 Peters SAE, Huxley RR \& Woodward M. Diabetes as risk factor for incident coronary heart disease in women compared with men: a systematic review and meta-analysis of 64 cohorts including 858,507 individuals and 28,203 coronary events. Diabetologia 201457 1542-1551. (https://doi.org/10.1007/s00125-014-3260-6)

5 Chen HF, Lee SP \& Li CY. Sex differences in the incidence of hemorrhagic and ischemic stroke among diabetics in Taiwan. Journal of Women's Health 200918 647-654. (https://doi.org/10.1089/ jwh.2008.0918)

6 Tancredi M, Rosengren A, Svensson AM, Kosiborod M, Pivodic A, Gudbjörnsdottir S, Wedel H, Clements M, Dahlqvist S \& Lind M. Excess mortality among persons with Type 2 diabetes. New England Journal of Medicine 2015373 1720-1732. (https://doi.org/10.1056/ NEJMoa1504347)

7 Almdal T, Scharling H, Jensen JS \& Vestergaard H. The independent effect of type 2 diabetes mellitus on ischemic heart disease, stroke, and death: a population-based study of 13,000 men and women with 20 years of follow-up. Archives of Internal Medicine 2004164 1422-1426. (https://doi.org/10.1001/archinte.164.13.1422)

8 Taking sex into account in medicine. Lancet 2011378 1826. (https:// doi.org/10.1016/S0140-6736(11)61795-9)

9 Peters SA, Huxley RR \& Woodward M. Smoking as a risk factor for stroke in women compared with men: a systematic review and meta-analysis of 81 cohorts, including 3,980,359 individuals and 42,401 strokes. Stroke 201344 2821-2828. (https://doi.org/10.1161/ STROKEAHA.113.002342)

10 Peters SAE, Huxley RR \& Woodward M. Diabetes as a risk factor for stroke in women compared with men: a systematic review and metaanalysis of 64 cohorts, including 775,385 individuals and 12,539 strokes. Lancet 2014383 1973-1980. (https://doi.org/10.1016/S01406736(14)60040-4)

11 Peters SA, Huxley RR, Sattar N \& Woodward M. Sex differences in the excess risk of cardiovascular diseases associated with Type 2 diabetes: potential explanations and clinical implications. Current Cardiovascular Risk Reports 20159 36. (https://doi.org/10.1007/ s12170-015-0462-5)

12 Huxley R, Barzi F \& Woodward M. Excess risk of fatal coronary heart disease associated with diabetes in men and women: meta-analysis of 37 prospective cohort studies. BMJ 2006332 73-78. (https://doi. org/10.1136/bmj.38678.389583.7C)

13 Barone BB, Yeh HC, Snyder CF, Peairs KS, Stein KB, Derr RL, Wolff AC $\&$ Brancati FL. Long-term all-cause mortality in cancer patients with preexisting diabetes mellitus: a systematic review and meta-analysis. JAMA 2008300 2754-2764. (https://doi.org/10.1001/jama.2008.824)

14 Stang A. Critical evaluation of the Newcastle-Ottawa scale for the assessment of the quality of nonrandomized studies in metaanalyses. European Journal of Epidemiology 201025 603-605. (https:// doi.org/10.1007/s10654-010-9491-z) 
15 Panic N, Leoncini E, de Belvis G, Ricciardi W \& Boccia S. Evaluation of the endorsement of the preferred reporting items for systematic reviews and meta-analysis (PRISMA) statement on the quality of published systematic review and meta-analyses. PLOS ONE $2013 \mathbf{8}$ e83138. (https://doi.org/10.1371/journal.pone.0083138)

16 Higgins JPT \& Thompson SG. Quantifying heterogeneity in a metaanalysis. Statistics in Medicine 200221 1539-1558. (https://doi. org/10.1002/sim.1186)

17 Duval S \& Tweedie R. Trim and fill: A simple funnel-plot-based method of testing and adjusting for publication bias in metaanalysis. Biometrics 200056 455-463. (https://doi.org/10.1111/ j.0006-341X.2000.00455.x)

18 Preis S, Hwang SJ, Coady S \& Pencina MJ, D'Agostino RB Sr, Savage P, Levy D \& Fox C. Trends in all-cause and cardiovascular disease mortality among women and men with and without diabetes mellitus in the Framingham Heart Study, 1950 to 2005. Circulation 2009119 1728-1735. (https://doi.org/10.1161/ CIRCULATIONAHA.108.82917)

19 Jarrett RJ, Mccartney P \& Keen H. The Bedford survey: ten year mortality rates in newly diagnosed diabetics, borderline diabetics and normoglycaemic controls and risk indices for coronary heart disease in borderline diabetics. Diabetologia 198222 79-84. (https://doi. org/10.1007/BF00254833)

20 Vilbergsson S, Sigurdsson G, Sigvaldason H \& Sigfusson N. Coronary heart disease mortality amongst non-insulin-dependent diabetic subjects in Iceland: the independent effect of diabetes. The Reykjavik Study 17-year follow up. Journal of Internal Medicine 1998244 309-316. (https://doi.org/10.1046/j.1365-2796.1998.00368.x)

21 Tunstall-Pedoe H, Woodward M, Tavendale R, A'Brook R \& McCluskey MK. Comparison of the prediction by 27 different factors of coronary heart disease and death in men and women of the Scottish Heart Health Study: cohort study. BMJ 1997315 722-729. (https://doi.org/10.1136/bmj.315.7110.722)

22 Morrish NJ, Wang SL, Stevens LK, Fuller JH \& Keen H. Mortality and causes of death in the WHO Multinational Study of Vascular Disease in Diabetes. Diabetologia 200144 (Supplement 2) S14-S21. (https:// doi.org/10.1007/PL00002934)

23 Sievers ML, Nelson RG, Knowler WC \& Bennett PH. Impact of NIDDM on mortality and causes of death in pima Indians. Diabetes Care 1992 15 1541-1549. (https://doi.org/10.2337/diacare.15.11.1541)

24 Allemann S, Saner C, Zwahlen M, Christ ER, Diem P \& Stettler C. Long-term cardiovascular and non-cardiovascular mortality in women and men with type 1 and type 2 diabetes mellitus: a 30-year follow-up in Switzerland. Swiss Medical Weekly 2009139 576-583. (https://doi.org/smw-12785)

25 Nilsson PM, Johansson SE \& Sundquist J. Low educational status is a risk factor for mortality among diabetic people. Diabetic Medicine 199815 213-219. (https://doi.org/10.1002/(SICI)10969136(199803)15:3<213::AID-DIA569>3.0.CO;2-\#)

26 Collins VR, Dowse GK, Ram P, Cabealawa S \& Zimmet PZ. Noninsulin-dependent diabetes and 11-year mortality in Asian Indian and Melanesian Fijians. Diabetic Medicine 199613 125-132. (https://doi.org/10.1002/(SICI)1096-9136(199602)13:2<125::AIDDIA13>3.0.CO;2-P)

27 Damsgaard EM, Frøland A \& Mogensen CE. Over-mortality as related to age and gender in patients with established non-insulindependent diabetes mellitus. Journal of Diabetes and Its Complications 199711 77-82. (https://doi.org/10.1016/S1056-8727(97)00095-0)

28 Niskanen L, Turpeinen A, Penttilä I \& Uusitupa MI. Hyperglycemia and compositional lipoprotein abnormalities as predictors of cardiovascular mortality in type 2 diabetes: a 15-year follow-up from the time of diagnosis. Diabetes Care 199821 1861-1869. (https://doi. org/10.2337/diacare.21.11.1861)

29 Hu G, Jousilahti P, Qiao Q, Katoh S \& Tuomilehto J. Sex differences in cardiovascular and total mortality among diabetic and nondiabetic individuals with or without history of myocardial infarction.
Diabetologia 200548 856-861. (https://doi.org/10.1007/s00125-0051730-6)

30 Juutilainen A, Lehto S, Rönnemaa T, Pyörälä K \& Laakso M. Type 2 diabetes as a 'coronary heart disease equivalent': an 18-year prospective population-based study in Finnish subjects. Diabetes Care 200528 2901-2907. (https://doi.org/10.2337/diacare.28.12.2901)

31 Gatling W, Tufail S, Mullee MA, Westacott TA \& Hill RD. Mortality rates in diabetic patients from a community-based population compared to local age/sex matched controls. Diabetic Medicine 199714 316-320. (https://doi.org/10.1002/(SICI)10969136(199704)14:4<316::AID-DIA328>3.0.CO;2-0)

32 Wibell L, Nyström L, Ostman J, Arnqvist H, Blohmé G, Lithner F, Littorin B \& Sundkvist GIncreased mortality in diabetes during the first 10 years of the disease. A population-based Study (DISS) in Swedish adults 15-34 years old at diagnosis. Journal of Internal Medicine 2001249 263-270. (https://doi.org/10.1111/j.13652796.2001.00802.x)

33 Waernbaum I, Blohmé G, Ostman J, Sundkvist G, Eriksson J, Arnqvist H, Bolinder J \& Nyström L. Excess mortality in incident cases of diabetes mellitus aged 15 to 34 years at diagnosis: a population-based study (DISS) in Sweden. Diabetologia 200649 653-659. (https://doi.org/10.1007/s00125-005-0135-x)

34 de Marco R, Locatelli F, Zoppini G, Verlato G, Bonora E \& Muggeo M. Cause-specific mortality in type 2 diabetes. The Verona Diabetes Study. Diabetes Care 199922 756-761. (https://doi.org/10.2337/ diacare.22.5.756)

35 Simons LA, McCallum J, Friedlander Y \& Simons J. Diabetes, mortality and coronary heart disease in the prospective Dubbo study of Australian elderly. Australian and New Zealand Journal of Medicine 199626 66-74. (https://doi.org/10.1111/j.1445-5994.1996. tb02909.x)

36 Florkowski CM, Scott RS, Coope PA \& Moir CL. Predictors of mortality from type 2 diabetes mellitus in Canterbury, New Zealand; a ten-year cohort study. Diabetes Research and Clinical Practice 2001 53 113-120. (https://doi.org/10.1016/S0168-8227(01)00246-7)

37 Baenadíez JM, Peñafiel J, Subirana I, Ramos R, Elosua R, Marínibañez A, Guembe MJ, Rigo F, Tormodíaz MJ \& Morenoiribas C. Risk of cause-specific death in individuals With diabetes: A competing risks analysis. Diabetes Care 201639 1987-1995. (https:// doi.org/10.2337/dc16-0614)

38 Mata-Cases M, Prado-Lacueva CD, Salido-Valencia V, FernándezBertolín E, Casermeiro-Cortés J, García-Durán M, Jabalera-López S \& Fernández-Sanmartín MI. Incidence of complications and mortality in a type 2 diabetes patient cohort study followed up from diagnosis in a primary healthcare centre. International Journal of Clinical Practice 201165 299-307. (https://doi.org/10.1111/j.17421241.2010.02503.x)

39 Gnavi R, Petrelli A, Demaria M, Spadea T, Carta Q \& Costa G. Mortality and educational level among diabetic and non-diabetic population in the Turin Longitudinal Study: a 9-year follow-up. International Journal of Epidemiology 200433 864-871. (https://doi. org/10.1093/ije/dyh089)

40 Oba S, Nagata C, Nakamura K, Takatsuka N \& Shimizu H. Selfreported diabetes mellitus and risk of mortality from all causes, cardiovascular disease, and cancer in Takayama: a population-based prospective cohort study in Japan. Journal of Epidemiology 200818 197-203. (https://doi.org/10.2188/jea.JE2008004)

41 Mulnier HE, Seaman HE, Raleigh VS, Soedamahmuthu SS, Colhoun HM \& Lawrenson RA. Mortality in people with type 2 diabetes in the UK. Diabetic Medicine 200623 516-521. (https://doi. org/10.1111/j.1464-5491.2006.01838.x)

42 Barnett KN, Ogston SA, McMurdo ME, Morris AD \& Evans JM. A 12-year follow-up study of all-cause and cardiovascular mortality among 10,532 people newly diagnosed with Type 2 diabetes in Tayside, Scotland. Diabetic Medicine 201027 1124-1129. (https://doi. org/10.1111/j.1464-5491.2010.03075.x) 
43 Roper NA, Bilous R, Kelly W, Unwin N \& Connolly V. Excess mortality in a population with diabetes and the impact of material deprivation: longitudinal, population based study. BMJ 2001322 1389-1393. (https://doi.org/10.1136/bmj.322.7299.1389)

44 Roche MM \& Wang PP. Sex differences in all-cause and cardiovascular mortality, hospitalization for individuals with and without diabetes, and patients with diabetes diagnosed early and late. Diabetes Care 201336 2582-2590. (https://doi.org/10.2337/dc12-1272)

45 Bo S, Ciccone G, Rosato R, Gancia R, Grassi G, Merletti F \& Pagano GF. Renal damage in patients with Type 2 diabetes: a strong predictor of mortality. Diabetic Medicine 200522 258-265. (https:// doi.org/10.1111/j.1464-5491.2004.01394.x)

46 Harding JL, Shaw JE, Peeters A, Guiver T, Davidson S \& Magliano DJ. Mortality trends among people with type 1 and type 2 diabetes in Australia: 1997-2010. Diabetes Care 201437 2579-2586. (https://doi. org/10.2337/dc14-0096)

47 Lin GM, Li YH, Lin CL, Wang JH \& Han CL. Gender differences in the impact of diabetes on mortality in patients with established coronary artery disease: A report from the Eastern Taiwan integrated health care delivery system of Coronary Heart Disease (ET-CHD) registry, 1997-2006. Journal of Cardiology 201361 393-398. (https:// doi.org/10.1016/j.jjcc.2013.02.007)

48 Guzder RN, Gatling W, Mullee MA \& Byrne CD. Early mortality from the time of diagnosis of Type 2 diabetes: a 5-year prospective cohort study with a local age- and sex-matched comparison cohort. Diabetic Medicine 200724 1164-1167. (https://doi.org/10.1111/j.14645491.2007.02223.x)

49 Schoepf D, Potluri R, Uppal H, Natalwala A, Narendran P \& Heun R. Type-2 diabetes mellitus in schizophrenia: increased prevalence and major risk factor of excess mortality in a naturalistic 7-year follow-up. European Psychiatry 201227 33-42. (https://doi. org/10.1016/j.eurpsy.2011.02.009)

50 Yu MK, Kim YJ, Park JY, Lee WJ \& Chang HJ. Mortality and causes of death in a national sample of type 2 diabetic patients in Korea from 2002 to 2013. Cardiovascular Diabetology 201615 131. (https://doi. org/10.1186/s12933-016-0451-0)

51 Taylor KS, Heneghan CJ, Farmer AJ, Fuller AM, Adler AI, Aronson JK $\&$ Stevens RJ. All-cause and cardiovascular mortality in middleaged people With Type 2 diabetes compared With people Without diabetes in a Large U.K. Primary Care Database. Diabetes Care 2013 36 2366-2371. (https://doi.org/10.2337/dc12-1513)

52 Won KB, Hur SH, Cho YK, Yoon HJ, Nam CW, Kim KB, Bae JH, Choi DJ, Ahn YK, Park JS et al. Comparison of 2-year mortality according to obesity in stabilized patients with type 2 diabetes mellitus after acute myocardial infarction: results from the DIAMOND prospective cohort registry. Cardiovascular Diabetology 201514 141. (https://doi.org/10.1186/s12933-015-0305-1)

53 Seeman T, Mendes de Leon C, Berkman L \& Ostfeld A. Risk factors for coronary heart disease among older men and women: a prospective study of community-dwelling elderly. American Journal of Epidemiology 1993138 1037-1049. (https://doi.org/10.1093/ oxfordjournals.aje.a116822)

54 Laakso M, Rönnemaa T, Lehto S, Puukka P, Kallio V \& Pyörälä K. Does NIDDM increase the risk for coronary heart disease similarly in both low- and high-risk populations? Diabetologia 199538 487-493. (https://doi.org/10.1007/BF00410288)

55 Jousilahti P, Vartiainen E, Tuomilehto J \& Puska P. Sex, age, cardiovascular risk factors, and coronary heart disease: a prospective follow-up study of 14786 middle-aged men and women in Finland. Circulation 199999 1165-1172. (https://doi.org/10.1161/01. CIR.99.9.1165)

56 Kuusisto J, Mykkänen L, Pyörälä K \& Laakso M. NIDDM and its metabolic control predict coronary heart disease in elderly subjects. Diabetes 199443 960-967. (https://doi.org/10.2337/diab.43.8.960)

57 Kalyani RR, Lazo M, Ouyang P, Turkbey E, Chevalier K, Brancati F, Becker D \& Vaidya D. Sex differences in diabetes and risk of incident coronary artery disease in healthy young and middle-aged adults. Diabetes Care 201437 830-838. (https://doi.org/10.2337/dc13-1755)

58 Matsunaga M, Yatsuya H, Iso H, Yamashita K, Li Y, Yamagishi K, Tanabe N, Wada Y, Wang C, Ota A et al. Similarities and differences between coronary heart disease and stroke in the associations with cardiovascular risk factors: the Japan Collaborative Cohort Study. Atherosclerosis 2017261 124-130. (https://doi.org/10.1016/j. atherosclerosis.2017.03.003)

59 Butter WJ Jr, Ostrander LD, Carman WJ \& Lamphiear DE. Mortality from coronary heart disease in the Tecumseh study long-term effect of diabetes mellitus, glucose tolerance and other risk factors. American Journal of Epidemiology 1985121 541-547. (https://doi. org/10.1093/oxfordjournals.aje.a114031)

60 Vilbergsson S, Sigurdsson G, Sigvaldason H \& Sigfusson N. Coronary heart disease mortality amongst non-insulin-dependent diabetic subjects in Iceland: the independent effect of diabetes. The Reykjavik Study 17-year follow up. Journal of Internal Medicine $199824 \mathbf{4}$ 309-316. (https://doi.org/10.1046/j.1365-2796.1998.00368.x)

61 Pan W, Cedres LB, Liu K, Dyer A, Schoenberger JA, Shekelle RB, Stamler R, Smith D, Collette P \& Stamler J. Relationship of clinical diabetes and asymptomatic hyperglycemia to risk of coronary heart disease mortality in men and women. American Journal of Epidemiology 1986123 504-516. (https://doi.org/10.1093/ oxfordjournals.aje.a114266)

62 Natarajan S, Liao Y, Sinha D, Cao G, Mcgee DL \& Lipsitz SR. Sex differences in the effect of diabetes duration on coronary heart disease mortality. Archives of Internal Medicine 2005165 430-435. (https://doi.org/10.1001/archinte.165.4.430)

63 Natarajan S, Liao Y, Cao G, Lipsitz SR \& Mcgee DL. Sex differences in risk for coronary heart disease mortality associated With diabetes and established coronary heart disease. Archives of Internal Medicine 2003163 1735-1740. (https://doi.org/10.1001/ archinte.163.14.1735)

64 Barrettconnor EL, Cohn BA, Wingard DL \& Edelstein SL. Why is diabetes mellitus a stronger risk factor for fatal ischemic heart disease in women than in men? The Rancho Bernardo Study. JAMA 1991 265 627-631. (https://doi.org/10.1001/jama.265.5.627)

65 Imazu M, Sumii K, Yamamoto H, Toyofuku M, Tadehara F, Okubo M, Yamakido M, Kohno N \& Onaka AT. Influence of type 2 diabetes mellitus on cardiovascular disease mortality: findings from the Hawaii-Los Angeles-Hiroshima study. Diabetes Research and Clinical Practice 200257 61-69. (https://doi.org/10.1016/S01688227(02)00016-5)

66 Fraser GE, Strahan TM, Sabaté J, Beeson WL \& Kissinger D. Effects of traditional coronary risk factors on rates of incident coronary events in a low-risk population. The Adventist Health Study. Circulation 199286 406-413. (https://doi.org/10.1161/01.CIR.86.2.406)

67 Huxley RR, Peters SA, Mishra GD \& Woodward M. Risk of all-cause mortality and vascular events in women versus men with type 1 diabetes: a systematic review and meta-analysis. Lancet Diabetes and Endocrinology 20153 198-206. (https://doi.org/10.1016/S22138587(14)70248-7)

68 Prospective Studies C \& Asia Pacific Cohort Studies C. Sex-specific relevance of diabetes to occlusive vascular and other mortality: a collaborative meta-analysis of individual data from 980793 adults from 68 prospective studies. Lancet Diabetes and Endocrinology 20186 538-546. (https://doi.org/10.1016/S2213-8587(18)30079-2)

69 Peters SA, Huxley RR \& Woodward M. Diabetes as risk factor for incident coronary heart disease in women compared with men: a systematic review and meta-analysis of 64 cohorts including 858,507 individuals and 28,203 coronary events. Diabetologia 201457 1542-1551. (https://doi.org/10.1007/s00125-014-3260-6)

70 Logue J, Walker JJ, Colhoun HM, Leese GP, Lindsay RS, McKnight JA, Morris AD, Pearson DW, Petrie JR, Philip S et al. Do men develop type 2 diabetes at lower body mass indices than women? Diabetologia 201154 3003-3006. (https://doi.org/10.1007/s00125-011-2313-3) 
71 Paul S, Thomas G, Majeed A, Khunti K \& Klein K. Women develop type 2 diabetes at a higher body mass index than men. Diabetologia 201255 1556-1557. (https://doi.org/10.1007/s00125-012-2496-2)

72 Kwon SK. Women are diagnosed with type 2 diabetes at higher body mass indices and older ages than men: Korea national health and nutrition examination survey 2007-2010. Diabetes and Metabolism Journal 201438 74-80. (https://doi.org/10.4093/dmj.2014.38.1.74)

73 Logue J, Walker JJ, Colhoun HM, Leese GP, Lindsay RS, McKnight JA, Morris AD, Pearson DW, Petrie JR, Philip S et al. Do men develop type 2 diabetes at lower body mass indices than women? Diabetologia 201154 3003-3006. (https://doi.org/10.1007/s00125-011-2313-3)

74 Peters SA, Huxley RR \& Woodward M. Diabetes as risk factor for incident coronary heart disease in women compared with men: a systematic review and meta-analysis of 64 cohorts including 858,507 individuals and 28,203 coronary events. Diabetologia 201457 1542-1551. (https://doi.org/10.1007/s00125-014-3260-6)

75 Krämer HU, Raum E, Rüter G, Schöttker B, Rothenbacher D, Rosemann T, Szecsenyi J \& Brenner H. Gender disparities in diabetes and coronary heart disease medication among patients with type 2 diabetes: results from the DIANA study. Cardiovascular Diabetology 201211 88. (https://doi.org/10.1186/1475-2840-11-88)

76 Brännström J, Hamberg K, Molander L, Lövheim H \& Gustafson Y. Gender disparities in the pharmacological treatment of cardiovascular disease and diabetes mellitus in the very old: an epidemiological, cross-sectional survey. Drugs and Aging 201128 993-1005. (https://doi.org/10.2165/11594730-000000000-00000)

77 Kalyani RR, Lazo M, Ouyang P, Turkbey E, Chevalier K, Brancati F, Becker D \& Vaidya D. Sex differences in diabetes and risk of incident coronary artery disease in healthy young and middle-aged adults. Diabetes Care 201437 830-838. (https://doi.org/10.2337/dc13-1755)

78 Cull CA, Neil HAW \& Holman RR. Changing aspirin use in patients with Type 2 diabetes in the UKPDS. Diabetic Medicine 200421 1368-1371. (https://doi.org/10.1111/j.1464-5491.2004.01328.x)

79 Antithrombotic Trialists' (ATT) Collaboration, Baigent C, Blackwell L, Collins R, Emberson J, Godwin J, Peto R, Buring J, Hennekens C, Kearney $\mathrm{P}$ et al. Aspirin in the primary and secondary prevention of vascular disease: collaborative meta-analysis of individual participant data from randomised trials. Lancet 2009373 1849-1860. (https:// doi.org/10.1016/S0140-6736(09)60503-1)

80 De Berardis G, Sacco M, Strippoli GF, Pellegrini F, Graziano G, Tognoni G \& Nicolucci A. Aspirin for primary prevention of cardiovascular events in people with diabetes: meta-analysis of randomised controlled trials. BMJ 2009339 b4531. (https://doi. org/10.1136/bmj.b4531)

81 Franzini L, Ardigò D, Cavalot F, Miccoli R, Rivellese AA, Trovati M, Zavaroni I \& Vaccaro O. Women show worse control of type 2 diabetes and cardiovascular disease risk factors than men: results from the MIND.IT Study Group of the Italian Society of Diabetology. Nutrition, Metabolism, and Cardiovascular Diseases 201323 235-241. (https://doi.org/10.1016/j.numecd.2011.12.003)

82 Winston GJ, Barr RG, Carrasquillo O, Bertoni AG \& Shea S. Sex and racial/ethnic differences in cardiovascular disease risk factor treatment and control among individuals with diabetes in the Multi-Ethnic Study of Atherosclerosis (MESA). Diabetes Care 200932 1467-1469. (https://doi.org/10.2337/dc09-0260)
83 Kautzky-Willer A, Kosi L, Lin J \& Mihaljevic R. Gender-based differences in glycaemic control and hypoglycaemia prevalence in patients with type 2 diabetes: results from patient-level pooled data of six randomized controlled trials. Diabetes, Obesity and Metabolism 201517 533-540. (https://doi.org/10.1111/dom.12449)

84 Sämann A, Lehmann T, Heller T, Müller N, Hartmann P, Wolf GB \& Müller UA. A retrospective study on the incidence and risk factors of severe hypoglycemia in primary care. Family Practice 201330 290-293. (https://doi.org/10.1093/fampra/cms071)

85 Miller ME, Bonds DE, Gerstein HC, Seaquist ER, Bergenstal RM, Calles-Escandon J, Childress RD, Craven TE, Cuddihy RM, Dailey G et al. The effects of baseline characteristics, glycaemia treatment approach, and glycated haemoglobin concentration on the risk of severe hypoglycaemia: post hoc epidemiological analysis of the ACCORD study. BMJ 2010340 b5444. (https://doi.org/10.1136/bmj. b5444)

86 Howard VJ, Madsen TE, Kleindorfer DO, Judd SE, Rhodes JD, Soliman EZ, Kissela BM, Safford MM, Moy CS, McClure LA et al. Sex and race differences in the association of incident ischemic stroke With risk factors. JAMA Neurology 201810 E1-E8. (https://doi. org/10.1001/jamaneurol.2018.3862)

87 Ding EL, Song Y, Malik VS \& Liu S. Sex differences of endogenous sex hormones and risk of type 2 diabetes: a systematic review and meta-analysis. JAMA 2006295 1288-1299. (https://doi.org/10.1001/ jama.295.11.1288)

88 Barrett-Connor E. The Rancho Bernardo Study 40 years studying why women have less heart disease than men and how diabetes modifies women's usual cardiac protection. Global Heart 20138 95-104. (https://doi.org/10.1016/j.gheart.2012.12.002).

89 Kalyani RR, Franco M, Dobs AS, Ouyang P, Vaidya D, Bertoni A, Gapstur SM \& Golden SH. The association of endogenous sex hormones, adiposity, and insulin resistance with incident diabetes in postmenopausal women. Journal of Clinical Endocrinology and Metabolism 200994 4127-4135. (https://doi.org/10.1210/jc.20090910)

90 Wannamethee SG, Papacosta O, Lawlor DA, Whincup PH, Lowe GD, Ebrahim S \& Sattar N. Do women exhibit greater differences in established and novel risk factors between diabetes and non-diabetes than men? The British Regional Heart Study and British Women's Heart Health Study. Diabetologia 201255 80-87. (https://doi. org/10.1007/s00125-011-2284-4)

91 Mansfield MW, Heywood DM \& Grant PJ. Sex differences in coagulation and fibrinolysis in white subjects with non-insulindependent diabetes mellitus. Arteriosclerosis, Thrombosis, and Vascular Biology 199616 160-164. (https://doi.org/10.1161/01. ATV.16.1.160)

92 Donahue RP, Rejman K, Rafalson LB, Dmochowski J, Stranges S \& Trevisan M. Sex differences in endothelial function markers before conversion to pre-diabetes: does the clock start ticking earlier among women? The Western New York Study. Diabetes Care 200730 354-359. (https://doi.org/10.2337/dc06-1772)

93 Singer JR, Palmas W, Teresi J, Weinstock R, Shea S \& Luchsinger JA. Adiponectin and all-cause mortality in elderly people with type 2 diabetes. Diabetes Care 201235 1858-1863. (https://doi.org/10.2337/ dc11-2215)

Received 27 September 2018

Revised version received 23 December 2018

Accepted 21 January 2019 